Gut, 1977, 18, 462-467

\title{
Gastric emptying in diabetic autonomic neuropathy
}

\author{
I. W. CAMPBEll, R. C. HEADiNG, P. TOTHILl, T. A. S. BUist, D. J. EWING, \\ AND B. F. CLARKE
}

From the Diabetic and Dietetic Department, University Departments of Therapeutics, Medical Physics and Medicine, and Department of Radiology, The Royal Infirmary, Edinburgh

SUMMARY Gastric emptying was studied in 12 diabetic patients, six with and six without objective evidence of autonomic neuropathy and in 20 non-diabetic controls, using a double isotope scintiscanning technique which differentiated between solid and liquid emptying. Three patients with autonomic neuropathy exhibited gastric stasis, although this was detected by conventional radiology in only one. Neither the patients with stasis nor those without exhibited abnormally rapid early gastric emptying. In patients without stasis, the normal differentiation between solid and liquid emptying was impaired, suggesting an abnormality of antral peristalsis not attributable to vagal denervation. Both intravenous and oral metoclopramide produced symptomatic improvement in two patients with gastric stasis and restored their gastric emptying to normal.

Delayed gastric emptying as a diabetic complication, which was first clearly described by Rundles in 1945, became generally recognised when Kassander (1958) introduced the descriptive term 'gastroparesis diabeticorum'. Although the condition seems to be uncommon, with a reported prevalence of less than 1 in 1000 diabetics (Zitomer et al., 1968), this figure probably relates to patients with obvious symptoms; subclinical impairment of gastric emptying may be more frequent. When gastric stasis does occur, the symptoms of abdominal distension, nausea, and vomiting may cause the patient considerable distress. Diabetic control may be difficult to maintain and, in insulin-dependent diabetics, frequent hypoglycaemic attacks may occur (Campbell and Conway, 1960). The treatment of gastric stasis in diabetics has remained unsatisfactory (Katz and Spiro, 1966).

The delay in gastric emptying has been attributed to vagal damage occurring as part of a more generalised autonomic neuropathy (Kassander, 1958; Wooten and Meriwether, 1961; Vinnik et al., 1962). However, in a recent study using a gamma camera method, no difference in gastric emptying between control subjects and diabetic patients with or without autonomic neuropathy was found (Scarpello et al., 1976). In the present study, gastric emptying was measured by a scintiscanning technique which

Received for publication 10 December 1976 differentiated between solid and liquid emptying (Heading et al., 1976) in two groups of diabetics, one with and one without objective evidence of autonomic neuropathy as assessed by cardiovascular reflexes (Ewing et al., 1973). In addition, a preliminary study was made of the effect of metoclopramide on gastric stasis.

\section{Methods}

Twelve male diabetics were selected for study. Six patients (numbers 1-6) had clinical features of autonomic neuropathy (Table 1) and were all shown to have abnormal cardiovascular reflexes-namely, an impaired heart rate response to the Valsalva manoeuvre, an abnormal blood pressure response to sustained handgrip and a postural fall in systolic blood pressure of at least $30 \mathrm{~mm} \mathrm{Hg}$ (Ewing et al., 1973). Patients 1,3 , and 5 had symptoms suggestive of gastric stasis with intermittent nausea and a feeling of fullness after meals, whereas patients 2,4 , and 6 had no gastrointestinal symptoms. The other six diabetic patients (numbers 7-12), subsequently referred to as the diabetic controls, had no clinical evidence of autonomic neuropathy and had normal cardiovascular reflexes. All patients were receiving treatment with insulin apart from patients nos. 2 and 10 who were receiving chlorpropramide. No diabetic was being treated with a biguanide. The two groups of diabetics were matched for mean age and duration of diabetes. Twenty patients without known gastro- 
Table 1 Details of six diabetic patients with autonomic neuropathy

\begin{tabular}{|c|c|c|c|c|c|c|c|c|}
\hline \multirow{2}{*}{$\begin{array}{l}\text { Patient } \\
\text { no. }\end{array}$} & \multirow{2}{*}{$\begin{array}{l}\text { Age } \\
(y r)\end{array}$} & \multirow{2}{*}{$\begin{array}{l}\text { Duration of } \\
\text { diabetes }(y r)\end{array}$} & \multicolumn{6}{|c|}{ Clinical manifestations of autonomic neuropathy } \\
\hline & & & $\begin{array}{l}\text { Epigastric } \\
\text { fullness, } \\
\text { nausea }\end{array}$ & $\begin{array}{l}\text { Postural } \\
\text { hypotension }\end{array}$ & Impotence & Diarrhoea & $\begin{array}{l}\text { Sweating } \\
\text { abnormalities* }\end{array}$ & $\begin{array}{l}\text { Hypoglycaemic } \\
\text { unawareness }\end{array}$ \\
\hline $\begin{array}{l}1 \\
2 \\
3 \\
4 \\
5 \\
6\end{array}$ & $\begin{array}{l}52 \\
47 \\
64 \\
54 \\
33 \\
63\end{array}$ & $\begin{array}{r}11 \\
23 \\
3 \\
18 \\
17 \\
11\end{array}$ & $\begin{array}{l}+ \\
\overline{+} \\
- \\
+ \\
-\end{array}$ & $\begin{array}{l}+ \\
+ \\
+ \\
+ \\
+ \\
+\end{array}$ & $\begin{array}{l}+ \\
+ \\
+ \\
+ \\
+ \\
+\end{array}$ & $\begin{array}{l}+ \\
- \\
- \\
+ \\
-\end{array}$ & $\begin{array}{l}\overrightarrow{+} \\
+ \\
+ \\
+ \\
-\end{array}$ & $\begin{array}{l}- \\
\overline{+} \\
+ \\
+ \\
-\end{array}$ \\
\hline
\end{tabular}

*Patients 2, 4, and 5 had diminished sweating in the legs and patient 3 had gustatory sweating.

intestinal disease formed a group of non-diabetic controls.

One week before the gastric emptying study, all the diabetic patients had a conventional upper alimentary barium examination (swallow, meal, and follow-through) performed by one of the authors (TASB), who was not told which patients had autonomic neuropathy.

Gastric emptying rates were assessed using a sequential scintiscanning method which provides information about the solid and liquid components of a standard meal (Heading et al., 1976). After fasting overnight, each subject ingested a meal of $20 \mathrm{~g}$ cornflakes, $15 \mathrm{~g}$ sugar (sucrose), and $150 \mathrm{ml}$ milk which contained two gamma-emitting radioactive markers. Indium-113m DTPA acted as a marker for the liquid component and technetium$99 \mathrm{~m}$ sulphur colloid, incorporated in approximately 30 small pieces of Perspex-coated filter paper, acted as a marker of the solid component. Ten minutes after ingestion of the meal each patient was positioned supine under a double-headed rectilinear scanner and the opposed detectors used to produce anterior and posterior abdominal scans for each of the two isotopes. Further scans were performed at approximately $30,60,90$, and 120 minutes after the meal; between scans the patients sat quietly in a chair. Quantitation of the amount of each isotope present in the stomach on successive scans was obtained by dot counting.

Liquid marker emptying during the period 0-10 minutes was taken to represent the early phase of gastric emptying and this was measured in all diabetics and in 14 of the 20 non-diabetic controls. Subsequent emptying of the liquid marker-that is during the period 10-120 minutes-was measured in all patients and the emptying rates expressed as half times $\left(T_{\xi}\right)$. Comparison of solid and liquid marker emptying was initially undertaken during the period between the second and final scans - that is, approximately 30-120 minutes after meal ingestion-with the intention of avoiding the early phase of emptying which we thought might complicate interpretation of the data. Subsequently, it became apparent that knowledge of solid emptying during the early phase was desirable and for some later patients the scanning procedure was modified to measure early emptying of both markers simultaneously (Heading et al., 1976).

The effect of metoclopramide (Maxolon) on gastric emptying was assessed in two diabetics (patients 1 and 5) who were shown to have gastric stasis in the initial scanning study. The third subject with gastric stasis (patient 3 ) became ill and was not available for study. Six weeks after the initial measurement, the gastric emptying measurements were repeated with intravenous administration of $10 \mathrm{mg}$ metoclopramide five minutes before meal ingestion. After a further week the patients started oral metoclopramide, one $10 \mathrm{mg}$ tablet three times daily before meals, which was continued for two weeks. A third emptying study was then performed; on this occasion the patients were given one $10 \mathrm{mg}$ metoclopramide tablet 20 minutes before the meal.

\section{Results}

On routine radiological examination with barium, four of the six diabetics with autonomic neuropathy (patients 1,2, 4, and 5) showed impaired oesophageal motility with tertiary concentrations. Only one (patient 5) was considered to have delayed gastric emptying. No abnormality was observed in the other two patients with autonomic neuropathy or in the six diabetic controls.

The gastric emptying $T_{t}$ values for the liquid marker are shown in Table 2. The diabetic controls had normal $T_{*}$ values as did three of the diabetics with autonomic neuropathy but the other three (patients 1, 3, and 5) exhibited gastric stasis with $\mathrm{T}_{t}$ values greater than 100 minutes. These latter three patients were those in whom gastric stasis had been 
Table 2 Gastric emptying $T_{\frac{1}{2}}$ values in diabetic patients with autonomic neuropathy (numbers 1-6), without autonomic neuropathy (numbers 7-12), and in non-diabetic controls

\begin{tabular}{ll}
\hline $\begin{array}{l}\text { Patient } \\
\text { number }\end{array}$ & $\begin{array}{l}\text { Emptying } T_{\frac{1}{2}} \\
(\text { min })\end{array}$ \\
\hline 1 & 106 \\
2 & 52 \\
3 & 103 \\
4 & 51 \\
5 & 205 \\
6 & 26 \\
7 & 52 \\
8 & 41 \\
9 & 41 \\
10 & 42 \\
11 & 20 \\
12 & 47 \\
Non-diabetic controls & $39 \pm 12$ \\
(n=20) & $($ mean \pm SD) \\
\hline
\end{tabular}

suspected clinically although only in patient 5 had delayed emptying been apparent on the barium examination.

In the nine diabetic patients without stasis-that is, those with normal $T_{ \pm}$values-and in the 20-nondiabetic controls, the patterns of solid and liquid marker emptying were compared (Fig. 1). This comparison was made from the second scan onwards and results in Fig. 1 therefore begin at approximately 30 minutes after meal ingestion. In the non-diabetic control group there was a clear difference in emptying patterns of the two markers, with the solid emptying more slowly than the liquid. In the diabetics, however, the patterns of solid and liquid marker emptying were much more alike and there was no statistically significant difference between them.

In four of the nine diabetics without stasis (patients 6, 8, 11, and 12) and in six of the 20 nondiabetic controls, measurements were made over the full 0-2 hour time period and the amount of each isotope in the stomach expressed as a percentage of the amount ingested (Fig. 2). Solid-liquid differentiation was again obvious in the non-diabetic controls, whereas it was much less apparent in the diabetics and did not attain statistical significance.

Figure 3 shows that early gastric emptying in the diabetics without gastric stasis and in the nondiabetic controls was similar. In the three patients with gastric stasis no measurable emptying occurred during this early period.

The effect of metoclopramide on gastric emptying in two patients with gastric stasis is summarised in Table 3. Both intravenous and oral metoclopramide restored the $T_{\frac{1}{2}}$ of the liquid marker to normal and solid marker emptying was also accelerated to within the control range. Both patients reported a marked improvement in their upper abdominal discomfort and nausea during the two weeks of oral metoclopramide therapy.

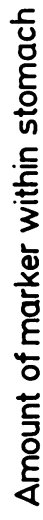

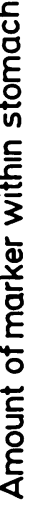

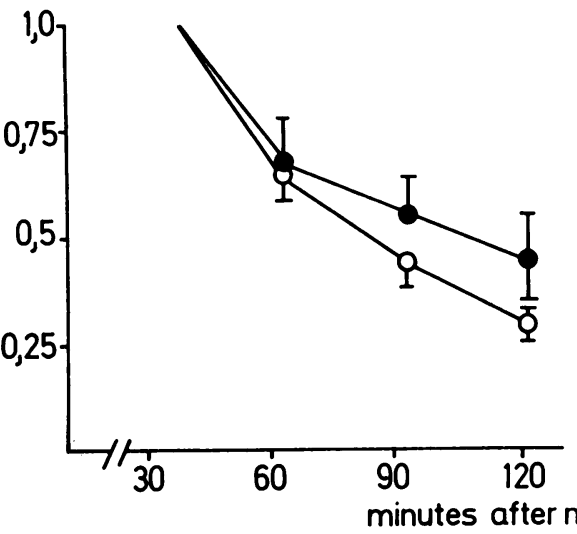

(a)

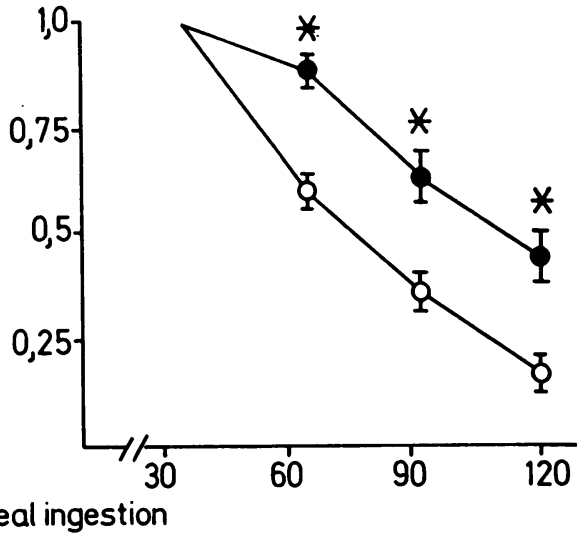

(b)

Fig. 1 Gastric emptying of solid and liquid markers during the period between the second and final scans in (a) nine diabetics and (b) 20 non-diabetic controls. The amount of each marker within the stomach at 30 minutes was arbitrarily defined as 1.0 and the amounts remaining at subsequent times are shown as means $\pm S E M$. Significant solid-liquid differences are indicated: $*=\mathrm{P}<0.001$ (paired $\mathrm{t}$ test). : solid marker, $\bigcirc$ : liquid marker. 


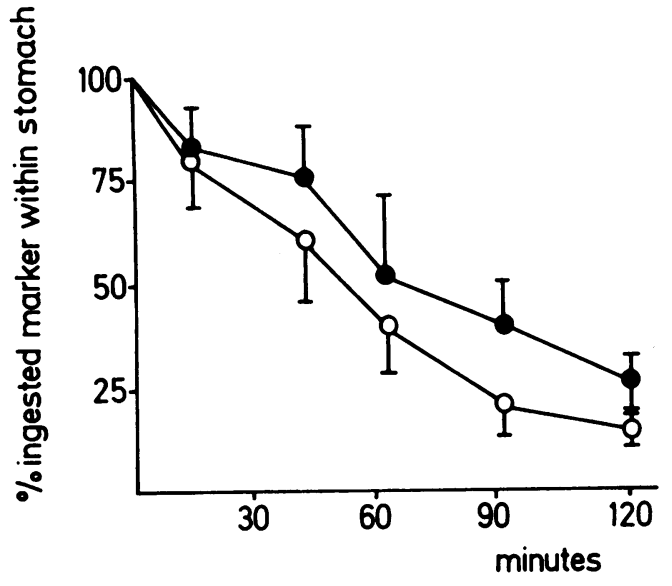

(a)

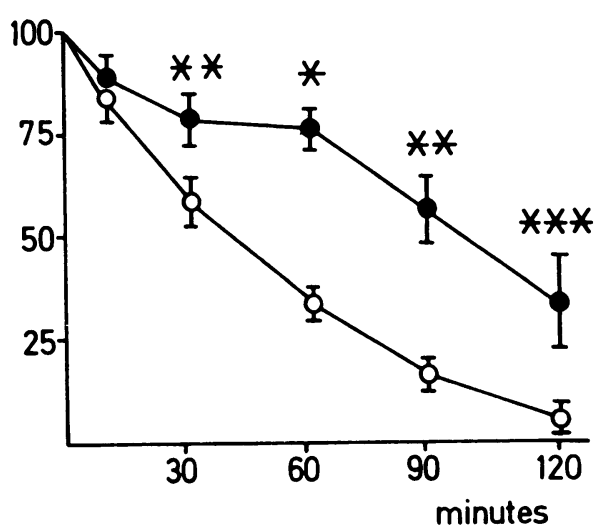

(b)

Fig. 2 Gastric emptying of solid (O) and liquid $(O)$ markers over the 120 minute period in (a) four diabetics and $(b)$ six non-diabetic controls. Data are means $\pm S E M$. Significant solid liquid differences are indicated: $*=\mathrm{P}<0.001, * *=\mathrm{P}<0.01, * * *=\mathrm{P}<0.05$ (paired $\mathrm{t}$ test).

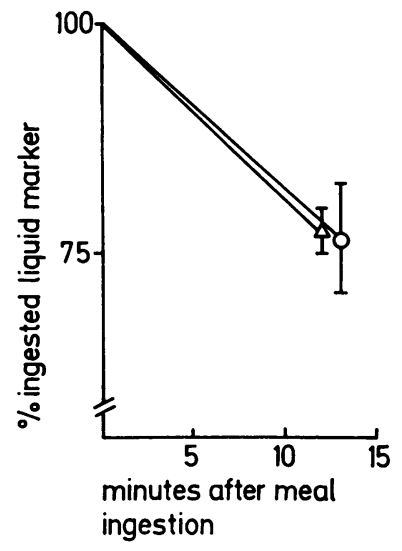

Fig. 3 Early gastric emptying of liquid marker in nine diabetics $(O)$ and 14 non-diabetic controls $(\triangle)$. Data are means $\pm S E M$.

\section{Discussion}

Diabetic gastric atony is believed to be similar to that seen after vagotomy (Kassander, 1958) and has been attributed to a vagal neuropathy (Wooten and Meriwether, 1961). The usual clinical presentation is a persistent feeling of fullness more marked after meals (Marshak and Maklansky, 1964), although some patients present acutely with nausea, vomiting, and upper gastrointestinal discomfort (Howland and Drinkard, 1963). Alternatively, the condition may be entirely asymptomatic and be discovered only by chance radiologically (Kassander, 1958). Conventional barium meal investigation reveals a dilated stomach with impaired peristalsis and delayed emptying despite a patulous pylorus (Hodges et al., 1947; Kassander, 1958; Marshak and Maklansky, 1964; Zitomer et al., 1968). Radiological and manometric abnormalities of oesophageal function commonly accompany gastric atony, but are usually asymptomatic and dysphagia is rare (Atkinson, 1976).

Previous studies of gastric emptying using saline meals (Dotevall, 1961) or a modified Hunt test meal (Aylett, 1965) have shown that emptying is slower than normal in diabetics. However, in these studies the patients were unselected as regards autonomic neuropathy. In addition, studies of gastric emptying

Table 3 Effect of metoclopramide on gastric emptying in two diabetic patients with gastric stasis

\begin{tabular}{|c|c|c|c|c|c|c|}
\hline \multirow[t]{2}{*}{ Patient } & \multicolumn{3}{|c|}{ Empt ving $T_{ \pm}$for liquid marker (min) } & \multicolumn{3}{|c|}{ Solid marker emptied in $2 \mathrm{~h}(\%$ amount ingested $)$} \\
\hline & $\begin{array}{l}\text { Without } \\
\text { metoclopramide }\end{array}$ & $\begin{array}{l}\text { After IV } \\
\text { metoclopramide }\end{array}$ & $\begin{array}{l}\text { After oral } \\
\text { metoclopramide }\end{array}$ & $\begin{array}{l}\text { Without } \\
\text { metoclopramide }\end{array}$ & $\begin{array}{l}\text { After IV } \\
\text { metoclopramide }\end{array}$ & $\begin{array}{l}\text { After oral } \\
\text { metoclopramide }\end{array}$ \\
\hline $\begin{array}{l}1 \\
5 \\
\text { Non-diabetic controls } \\
\quad(\text { means } \pm \text { SD) }\end{array}$ & $\begin{array}{l}106 \\
205 \\
39 \pm 12\end{array}$ & $\begin{array}{l}38 \\
22 \\
-\end{array}$ & $\begin{array}{l}40 \\
46 \\
-\end{array}$ & $\begin{array}{l}0 \\
0 \\
67 \pm 27\end{array}$ & $\begin{array}{r}48 \\
100 \\
-\end{array}$ & $\begin{array}{l}48 \\
60 \\
-\end{array}$ \\
\hline
\end{tabular}


based on the use of a liquid meal suffer the limitation that their relevance to emptying of more natural meals is uncertain. Scanning and gamma camera methods based on the incorporation of gammaemitting radioactive isotopes in food offer a means of assessing emptying after ingestion of ordinary meals but the heterogeneity of such meals may present a problem, as liquid and solids ingested together are not emptied from the stomach at the same rate (Thomas, 1957; Cooke, 1975). When an isotope marker of a meal is employed it is therefore necessary to define which component of the meal it represents. The technique employed in the present study uses two isotopes, one acting as a marker of the liquid component and the other of the solid component of the meal.

As in previous studies of diabetes (Mandelstam and Leiber, 1967; Mandelstam et al., 1969) radiological abnormalities of oesophageal motility were observed in some of our patients, although none had symptoms suggesting oesophageal dysfunction. These abnormalities were seen only in patients with other evidence of autonomic neuropathy; all six diabetics with normal vascular reflexes appeared to have normal oesophageal motility. Symptoms attributable to gastric stasis were present in three of the six patients with abnormal vascular reflexes and stasis was confirmed by the scanning method in all three. However, impaired gastric emptying was recognised radiologically in only one patient, thus suggesting that the conventional barium examination is an insensitive approach to detection of gastric stasis in diabetes.

Clinical and experimental studies have suggested that loss of normal vagal inervation of the stomach results in accelerated early gastric emptying (Clarke and Alexander-Williams, 1973; Wilbur and Kelly, 1973; Cooke, 1975). In the diabetic patients we were unable to identify any rapid early emptying of the liquid marker corresponding to this pattern. However, an unexpected finding in the diabetics without gastric stasis was the loss of solid-liquid differentiation. It would seem that this cannot be directly attributable to loss of vagal integrity, as differentiation is preserved after truncal vagotomy and pyloroplasty (Heading et al., 1975), whereas it is impaired by antrectomy in dogs (Dozois et al., 1971) and by partial gastrectomy in man (Heading et al., 1976) in accord with early evidence attributing solidliquid differentiation to antral peristalsis (Cannon, 1911). While we do not doubt the existence of autovagotomy in the diabetics with gastric stasis, the present findings thus imply that diabetics without gastric stasis may have an abnormality of antral peristalsis for which autovagotomy is not the explanation. As this impairment of differentiation tended to accelerate solid emptying, particularly during the first hour, it may in part account for the differences between the observations of Scarpello et al. (1976) made with a solid meal and those of earlier workers using liquid meals.

The treatment of gastric stasis in diabetes is unsatisfactory. Medical management consists of good diabetic control and small feeds (Kassander, 1958). Cholinergic agents such as bethanechol (Wooten and Meriwether, 1961) and cholinesterase inhibitors such as ambenonium chloride (Zitomer et al., 1968) and neostigmine (Marshak and Maklansky, 1964) have been used but the results are variable. Stasis is not improved by pyloroplasty or partial gastrectomy (Wooten and Meriwether, 1961; Wheelock and Marble, 1971).

Metoclopramide has been only briefly referred to as being of possible therapeutic benefit (Brownlee and Kroopf, 1974; Berkowitz 'et al., 1976). In nondiabetic subjects it is known to increase the strength of gastric contractions and to accelerate gastric emptying measured either radiologically (Kreel, 1970) or by dye-dilution technique (Connell and George, 1969). The drug has also been shown to reduce gastric stasis associated with surgical vagotomy (Hancock et al., 1974; Metzger et al., 1976). Metoclopramide is thought to act by enhancing the local effect of acetylcholine on gastric smooth muscle (Eismer, 1968), perhaps by increasing the actual amount of acetylcholine at post-ganglionic nerve endings (Hay, 1975). In the present study intravenous and oral metoclopramide both restored solid and liquid emptying to that seen in control subjects and both diabetics noted symptomatic improvement during the two weeks of oral therapy. These results suggest that oral metoclopramide may be helpful in the clinical management of gastric stasis in diabetics.

We are grateful to Miss W. Fleming for technical assistance.

\section{References}

Atkinson, M. (1976). Oesophageal motor changes in systemic disease. Clinics in Gastroenterology, 5, 119-133.

Aylett, P. (1965). Gastric emptying and secretion in patients with diabetes mellitus. Gut, 6, 262-265.

Berkowitz, D. M., Metzger, W. H., and Sturdevant, R. A. L. (1976). Oral metoclopramide in diabetic gastroparesis and in chronic gastric retention after gastric surgery (Abstr.). Gastroenterology, 70, 863.

Brownlee, M., and Kroopf, S. S. (1974). Metoclopramide for gastroparesis diabeticorum. New England Journal of Medicine, 291, 1257-1258.

Campbell, A., and Conway, H. (1960). Gastric retention and hypoglycaemia in diabetes. Scottish Medical Journal, 5, 167-168.

Cannon, W. B. (1911). The Mechanical Factors of Digestion. Arnold: London. 
Clarke, R. J., and Alexander-Williams, J. (1973). The effect of preserving antral innervation and of a pyloroplasty on gastric emptying after vagotomy in man. Gut, 14, 300-307.

Connell, A. M., and George, J. D. (1969). Effect of metoclopramide on gastric function in man. Gut, 10, 678-680.

Cooke, A. R. (1975). Control of gastric emptying and motility. Gastroenterology, 68, 804-816.

Dotevall, G. (1961). Gastric emptying in diabetes mellitus. Acta Medica Scandinavica, 170, 423-429.

Dozois, R. R., Kelly, K. A., and Code, C. F. (1971). Effect of distal antrectomy on gastric emptying of liquids and solids. Gastroenterology, 61, 675-681.

Eisner, M. (1968). Gastrointestinal effects of metoclopramide in man. In vitro experiments with human smooth muscle preparations. British Medical Journal, 4, 679-680.

Ewing, D. J., Campbell, I. W., Burt, A. A., and Clarke, B. F. (1973). Vascular reflexes in diabetic autonomic neuropathy, Lancet, 2, 1354-1356.

Hancock, B. D., Bowen-Jones, E., Dixon, R., Dymock, I. W., and Cowley, D. J. (1974). The effect of metoclopramide on gastric emptying of solid meals. Gut, 15, 462-467.

Hay, A. M. (1975). The mechanism of action of metoclopramide. Gut, 16, 403.

Heading, R. C., Tothill, P., McLoughlin, G. P., and Shearman, D. J. C. (1975). Effects of gastric surgery on differential emptying of solid and liquid components of the gastric contents. British Journal of Surgery, 62, 659.

Heading, R. C., Tothill, P., McLoughlin, G. P., and Shearman, D. J. C. (1976). Gastric emptying rate measurement in man: a double isotope scanning technique for simultaneous study of liquid and solid components of a meal. Gastroenterology, 71, 45-50.

Hodges, F. J., Rundles, R. W., and Hanelin, J. (1947). Roentgenologic study of small intestine. II. Dysfunction associated with neurologic diseases. Radiology, 49, 659-673.

Howland, W. J., and Drinkard, R. U. (1963). Acute diabetic gastric atony: gastroparesis diabeticorum. Journal of the American Medical Association, 185, 214-216.

Kassander, P. (1958). Asymptomatic gastric retention in diabetics (gastroparesis diabeticorum). Annals of Internal Medicine, 48, 797-812.
Katz, L. A., and Spiro, H. M. (1966). Gastrointestinal manifestations of diabetes. New England Journal of Medicine, 275, 1350-1361.

Kreel, L. (1970). The use of oral metoclopramide in the barium meal and follow-through examination. British Journal of Radiology, 43, 31-35.

Mandelstam, P., and Lieber, A. (1967). Esophageal dysfunction in diabetic neuropathy-gastroenteropathy. Journal of the American Medical Association, 201, 582-586.

Mandelstam, P., Siegel, C. I., Lieber, A., and Siegel, M. (1969). The swallowing disorder in patients with diabetic neuropathy-gastroenteropathy. Gastroenterology, 56, 1-12.

Marshak, R. H., and Maklansky, D. (1964). Diabetic gastropathy. American Journal of Digestive Diseases, 9, 366-370.

Metzger, W. H., Cano, R., and Sturdevant, R. A. L. (1976). Effect of metoclopramide in chronic gastric retention after gastric surgery. Gastroenterology, 71, 30-32.

Rundles, R. W. (1945). Diabetic neuropathy: general review with report of 125 cases. Medicine, 24, 111-160.

Scarpello, J. H. B., Barber, D. C., Hague, R. V., Cullen, D. R., and Sladen, G. E. (1976). Gastric emptying of solid meals in diabetics. British Medical Journal, 2, 671-673.

Thomas, J. E. (1957). Mechanics and regulation of gastric emptying. Physiological Reviews, 37, 453-474.

Vinnik, L. E., Kern, F. Jr, and Struthers, J. E. Jr. (1962). Malabsorption and the diarrhea of diabetes mellitus. Gastroenterology, 43, 507-520.

Wheelock, F. C. Jr, and Marble, A. (1971). Surgery and Diabetes, in Joslin's Diabetes Mellitus, pp. 599-620. Edited by A. Marble, P. White, R. F. Bradley, and L. P. Krall. Lea and Febiger: Philadelphia.

Wilbur, B. G., and Kelly, K. A. (1973). Effect of proximal gastric, complete gastric, and truncal vagotomy on canine gastric electric activity, motility and emptying. Annals of Surgery, 178, 295-303.

Wooten, R. L., and Meriwether, T. W. (1961). Diabetic gastric atony: a clinical study. Journal of the American Medical Association, 176, 1082-1087.

Zitomer, B. R., Gramm, H. F., and Kozak, G. P. (1968). Gastric neuropathy in diabetes mellitus: clinical and radiologic observations. Metabolism, 17, 199-211. 